\title{
Sulfur promoted low-temperature oxidation of methane over ceria supported platinum catalysts
}

\author{
Lisa Kylhammar, Per-Anders Carlsson * and Magnus Skoglundh \\ Department of Chemical and Biological Engineering and Competence Centre for Catalysis, Chalmers University of Technology, SE-412 96 \\ Göteborg, Sweden
}

\begin{abstract}
The influence of sulfur dioxide on methane oxidation over ceria supported platinum catalysts under lean conditions has been studied by transient flow reactor and in situ Fourier transform infrared spectroscopy experiments. The results show that sulfur dioxide can promote the oxidation of methane, here between 300 and $450^{\circ} \mathrm{C}$, although, as a function of time on stream, the promoting effect diminish and instead the methane oxidation becomes inhibited. We suggest that sulfate formation on ceria creates oxygen vacancies in the ceria that govern oxygen spillover leading to a lowering of detrimental oxygen coverage of platinum and/or decomposition of platinum oxide facilitating the dissociative methane adsorption. Eventually the ceria becomes saturated with sulfates and the oxygen dynamics in the platinum-ceria system settles. As a consequence, the system regresses towards highly oxidized platinum and/or otherwise active sites on the ceria or platinum-ceria boundary become blocked, which may explain the long-term inhibiting effect by $\mathrm{SO}_{2}$ exposure.
\end{abstract}

Key words: environmental catalysis; oxygen excess; catalytic activity; methane dissociation; metal-support interactions; transient analysis; in situ infrared spectroscopy; $\mathrm{Pt} / \mathrm{CeO}_{2}$

\section{Introduction}

The efforts to reduce emissions of greenhouse gases necessitates sustainable automotive transports, specifically addressing important areas as alternative fuels and combustion processes for more efficient propulsion. The leanburn gas engine provides an interesting alternative to conventional diesel or gasoline engines as the benefits of efficient combustion in oxygen excess are combined with superior properties of the fuel, i.e., biogas or natural gas. For example the amounts of formed carbon dioxide per produced quantity of combustion heat is relatively low [1] and the combustion process may be optimized such that negligible formation of soot is achieved without introducing a significant fuel penalty. However, as biogas and natural gas essentially consist of methane, which is a strong greenhouse gas, low levels of $\mathrm{CH}_{4}$ emissions must be targeted. As engine modifications alone are insufficient to comply with present emission regulations, catalytic exhaust aftertreatment technologies have to be considered. In this connection

\footnotetext{
* Corresponding author.

Email address: per-anders.carlsson@chalmers.se (Per-Anders Carlsson).
}

the main challenge is to find catalysts that are active for total oxidation of methane in the lean and cold exhausts, around $150^{\circ} \mathrm{C}$ for significant periods, which is considered representative for future efficient combustion concepts. The situation is further complicated by the presence of sulfur as the derived sulfur species often are poisons in many catalytic aftertreatment systems.

Practically, the most active catalysts for total oxidation of methane are palladium and/or platinum supported on metal oxides, e.g. $\mathrm{Al}_{2} \mathrm{O}_{3}, \mathrm{CeO}_{2}, \mathrm{ZrO}_{2}$ or combinations of such. Palladium has been widely recognized as the more preferred element to be used under oxygen excess [2-4]. However, Pd based catalysts are sensitive towards sulfur poisoning and even small amounts of sulfur containing species in the exhausts can cause deactivation of the oxidation function through the formation of stable palladium sulfates [3,5]. Contrarily, Pt based catalysts are more sulfur tolerant $[3,4]$ although the activity for methane oxidation is strongly dependent on the stoichiometry of the reactant gas mixture. For example, over $\mathrm{Pt} / \mathrm{Al}_{2} \mathrm{O}_{3}$ the oxidation of methane is inhibited under oxygen excess [2,6-10].

One approach to increase the methane conversion over $\mathrm{Pt} / \mathrm{Al}_{2} \mathrm{O}_{3}$ is to alternate the feed gas between netoxidizing and netreducing composition. By such means, temporarily 
high activity for methane oxidation closely associated with the changes of the gas composition has been observed [6-9]. Becker et al. [11] showed that the periods with high activity can be prolonged by using oxygen buffering ceria, instead of alumina, as support material for platinum. The high dynamics in the $\mathrm{Pt} / \mathrm{CeO}_{2}$ system may also explain the low light-off temperature $\left(\mathrm{T}_{50}\right)$ obtained for methane oxidation under continuously lean conditions but particularly active sites in the platinum-ceria boundary were also suggested by Carlsson et al. [12] explaining the difference as compared to $\mathrm{Pt} / \mathrm{Al}_{2} \mathrm{O}_{3}$. Another approach to circumvent oxygen inhibition is to include in the reactant feed compounds that can be more easily oxidized, for example longer saturated hydrocarbons (HC). Corro et al. [13] reported a decreased light-off temperature for methane oxidation over presulfated $\mathrm{Pt} / \mathrm{Al}_{2} \mathrm{O}_{3}$ by the addition of $\mathrm{C}_{2}-\mathrm{C}_{4}$ n-alkanes. Several authors have also reported on an increased activity for oxidation of short saturated hydrocarbons over $\mathrm{Pt} / \mathrm{Al}_{2} \mathrm{O}_{3}$ catalysts in the presence of sulfur, either through presulfation of the catalyst or by inclusion of low amounts of $\mathrm{SO}_{2}$ in the feed gas [14-20]. The mechanism for the promotional effect of sulfur on the activity for hydrocarbon oxidation is not fully understood. Wilson et al. [21] reported that the precursor mediated initial sticking probability of propane on a $\mathrm{Pt}(111)$ surface precovered with oxygen is significantly enhanced when $\mathrm{SO}_{2}$ is added prior to the introduction of propane. For supported catalysts this mechanism is likely of less importance keeping in mind that the degree of promotion has been shown to significantly depend on the type of support material. For example, promotional effects on oxidation of methane and/or propane have been seen for $\mathrm{Pt} / \mathrm{Al}_{2} \mathrm{O}_{3}$ [14-21] and $\mathrm{Pt} / \mathrm{Ce}_{0.67} \mathrm{Zr}_{0.33} \mathrm{O}_{2}$ [22] but not for $\mathrm{Pt} / \mathrm{SiO}_{2}$ [15-17]. The ability of the support to form sulfates is most likely of importance, which explains the difference between $\mathrm{SiO}_{2}$ and the former two support materials. It is also important which support sites that undergo sulfation. For example, Burch et al. [16] and Hubbard et al. [15] showed that the increase in surface acidity of the support upon $\mathrm{SO}_{2}$ exposure correlates poorly with the changes in activity for propane oxidation.

In the present study we investigate the promotional effect by sulfur dioxide on methane oxidation over ceria supported platinum catalysts under lean conditions. Here, ceria is chosen as support material for platinum due to the observed higher activity as compared to $\gamma$-alumina $[11,12]$ and that $\mathrm{SO}_{2}$ can be effectively adsorbed via formation of ad- $\mathrm{SO}_{x}$ species on ceria [23,24]. In the latter case we have previously reported the importance of physical contact between platinum and ceria for the $\mathrm{SO}_{2}$ adsorption [25]. Hence, it is likely that $\mathrm{SO}_{2}$ can influence the activity for methane oxidation by affecting the chemical state of $\mathrm{Pt}$ sites located at the platinum-ceria boundary, which may be especially active for methane oxidation [12].

\section{Experimental section}

To investigate the activity for methane oxidation of the $\mathrm{Pt} /$ ceria samples in the absence and presence of $\mathrm{SO}_{2}$, flow-reactor experiments with monolith samples were performed. Temperature programmed reaction experiments were performed to gain information of the extinction and ignition characteristics while transient $\mathrm{SO}_{2}$ exposure experiments were performed to study promotional and poisoning effects induced by sulfur. To gain mechanistic information on the role of $\mathrm{SO}_{2}$ for the promotional effect, in situ Fourier transformed infrared spectroscopy measurements were performed with powder samples in diffuse reflectance mode (DRIFTS). To facilitate comparisons of different experimental results, the monolith samples were coated with $\mathrm{Pt} /$ ceria powder sample from the same batch as the sample used for the DRIFTS experiments. Due to different reactor designs (flow characteristics and sample heating) the observed methane conversion varies somewhat between the flow reactor and DRIFTS experiments. Another important aspect for reliable comparison of results is that fresh monolith samples are used for each flow-reactor experiment. In order to investigate if comparable amount of catalyst and binder adhered to the monolith during coating, the specific surface area of the monolith sample was measured. As all monoliths have the same amount of coating $(200 \mathrm{mg})$ and the binder does not contribute to the high surface area of the samples, it can be assumed that the samples have comparable amounts of catalyst and binder if they also have comparable specific surface area.

\subsection{Catalyst preparation and characterisation}

Ceria powder (99.5 H.S.A. 514, Rhône-Poulenc) was heated in air at $600^{\circ} \mathrm{C}$ for $2 \mathrm{~h}$. The $\mathrm{Pt} /$ ceria powder catalyst was then prepared by impregnating the ceria powder with a water solution $(\mathrm{pH}=12)$ containing tetraammineplatinum(II)nitrate (4.0 wt\% Pt, Alfa Aesar) and ammonia using incipient wetness impregnation. After impregnation, the sample powder was frozen in liquid nitrogen, freeze-dried and calcined in air at $550^{\circ} \mathrm{C}$ for $15 \mathrm{~min}$. This temperature was reached using a linear heating ramp rate of $4.4^{\circ} \mathrm{C} / \mathrm{min}$ starting from room temperature. In order to obtain $4 \mathrm{wt} \% \mathrm{Pt}$ on ceria, the impregnation procedure was repeated three times. The surface area of the $4 \mathrm{wt} \%$ $\mathrm{Pt} /$ ceria powder sample was measured with $\mathrm{N}_{2}$ physisorption at $77 \mathrm{~K}$ (Micromeritics Tristar). Using the BET method for $\mathrm{P} / \mathrm{P}_{0}=0.05-0.20$, the specific surface area was calculated to be $156 \mathrm{~m}^{2} / \mathrm{g}$.

Two types of monolith samples were prepared with the 4 wt $\% \mathrm{Pt} /$ ceria and pure ceria powder, respectively. Monolith samples $(\varnothing=13 \mathrm{~mm}$, length $=15 \mathrm{~mm})$ were cut out from a commercial honeycomb cordierite structure (Corning) with 400 cpsi. The monolith samples were prepared by immersing the monolith body into a water slurry containing a binder (cerium acetate sol, $20 \mathrm{wt} \% \mathrm{CeO}_{2}$ (ACT), 10-20 
nm, Nyacol Nano Technologies) and the Pt/ceria and ceria powder, respectively. The samples were thereafter dried in air at $90^{\circ} \mathrm{C}$ for $5 \mathrm{~min}$ and then calcined at $550^{\circ} \mathrm{C}$ for $2 \mathrm{~min}$ also in air. This procedure was repeated until the washcoat loading was $200 \mathrm{mg}$. All samples were finally calcined in air at $550^{\circ} \mathrm{C}$ for $1 \mathrm{~h}$. The specific surface area was measured by $\mathrm{N}_{2}$ physisorption (Micromeritics ASAP 2010) using a specially designed sample holder suitable for monolith samples. According to the BET method the specific surface area of the $\mathrm{Pt} /$ ceria samples was calculated to be 130 $\mathrm{m}^{2} / \mathrm{g}$ coating $( \pm 3 \%)$. The corresponding area of a sample coated with $200 \mathrm{mg}$ of the binder was calculated to be 30 $\mathrm{m}^{2} / \mathrm{g}$ coating.

\subsection{Catalytic activity studies in continuous gas-flow reactor}

The continuous gas-flow reactor consists of a horizontal quartz tube $(\varnothing=15 \mathrm{~mm}$, length $=600 \mathrm{~mm})$ surrounded by a metal coil (Kanthal) for resistive heating (effective heating length $=450 \mathrm{~mm}$ ). The entire coil was insulated with a 20 mm layer of quartz wool (SUPERWOOL 607 HT, Thermal Ceramics) with an outer layer of aluminium foil. The gas temperature $15 \mathrm{~mm}$ upstream the sample was measured by a thermocouple (type K, Pentronic) and controlled with a PID regulator (Eurotherm 3508). In order to decrease axial temperature gradients in the sample monolith(s), blank cordierite monoliths functioning as heat radiation shields, were positioned up and downstream the sample. The temperature of both the blank and sample monoliths were measured with individual thermocouples. The feed gas was composed using a set of mass flow controllers (Bronkhorst LOW- $\Delta$ P-FLOW) and introduced to the reactor via air actuated high-speed gas valves (Valco, VICI). For analysis of the product stream, the reactor was equipped with a mass spectrometer (Airsense Compact, V\&F). The mass to charge ratio $(\mathrm{m} / \mathrm{z})$ for appropriate species were followed using chemical ionization with xenon for $\mathrm{m} / \mathrm{z} 64\left(\mathrm{SO}_{2}\right)$ and electron impact ionization for $\mathrm{m} / \mathrm{z} 2\left(\mathrm{H}_{2}\right), 12(\mathrm{C}), 15\left(\mathrm{CH}_{4}\right)$, $18\left(\mathrm{H}_{2} \mathrm{O}\right), 28(\mathrm{CO}), 32\left(\mathrm{O}_{2}\right.$ and $\left.\mathrm{S}\right), 33(\mathrm{HS})$ and $44\left(\mathrm{CO}_{2}\right)$.

\subsubsection{Temperature programmed reaction experiments}

Temperature programmed reaction (TPReaction) experiments were performed with two monolith samples. The samples were conditioned in a reaction mixture consisting of $0.05 \mathrm{vol} \% \mathrm{CH}_{4}$ (in the following vol\% is denoted \%) and $8 \% \mathrm{O}_{2}$ at $500^{\circ} \mathrm{C}$ for $60 \mathrm{~min}$, and the TPReaction experiments were started subsequently by ramping the temperature by $5^{\circ} \mathrm{C} / \mathrm{min}$ from 500 to $100^{\circ} \mathrm{C}$, dwelling for $20 \mathrm{~min}$ and then ramping back to $500^{\circ} \mathrm{C}$ and dwelling for another 20 min using the same gas mixture. This cooling-heating cycle was repeated three times (cycle 1-3) followed by another three cycles (cycle 4-6) where 20 ppm $\mathrm{SO}_{2}$ was added to the feed and, finally, three cycles (cycle 7-9) again without $\mathrm{SO}_{2}$. Argon was used as balance and the total gas flow was $1000 \mathrm{ml} / \mathrm{min}$ corresponding to a space velocity (GHSV) of $15000 \mathrm{~h}^{-1}$.

\subsubsection{Transient $\mathrm{SO}_{2}$ exposure experiments}

Transient $\mathrm{SO}_{2}$ exposure experiments were performed at isothermal conditions at $300,350,400$ and $500^{\circ} \mathrm{C}$ with one monolith sample. In all these experiments, the samples were conditioned in a reaction mixture consisting of $0.05 \% \mathrm{CH}_{4}$ and $8 \% \mathrm{O}_{2}$ at $500^{\circ} \mathrm{C}$ for $60 \mathrm{~min}$ and the temperature was thereafter decreased to the temperature to be studied and kept constant for another $60 \mathrm{~min}$ in the reaction mixture. Subsequently the $\mathrm{SO}_{2}$ exposure experiment was started by instantly introducing $100 \mathrm{ppm} \mathrm{SO}_{2}$ for a duration of $5 \mathrm{~min}$ to the reaction mixture and the response was followed until 20 min after the sulfur exposure period. In total, this sequence was repeated 24 times, which corresponds to $2 \mathrm{~h}$ of $\mathrm{SO}_{2}$ exposure. The space velocity (GHSV) was $30000 \mathrm{~h}^{-1}$.

\subsection{In situ DRIFT spectroscopy}

Time resolved in situ DRIFT spectroscopy experiments were performed with a Bio-Rad FTS6000 spectrometer equipped with a high-temperature reaction cell (Harrick Scientific, Praying Mantis). The sample was heated via the sample holder for which the temperature was measured with a thermocouple and controlled with a PID regulator (Eurotherm 2416). Gases were introduced to the reactor via individual mass flow controllers (Bronkhorst LOW$\triangle \mathrm{P}-\mathrm{FLOW}$. However, to facilitate precise transients, the $\mathrm{SO}_{2}$ feed was introduced via an air actuated high-speed gas valve (Valco, VICI). The product stream was analyzed by mass spectrometry (Balzers QuadStar 420) following the $\mathrm{m} / \mathrm{z} 2\left(\mathrm{H}_{2}\right), 15\left(\mathrm{CH}_{4}\right), 18\left(\mathrm{H}_{2} \mathrm{O}\right), 28(\mathrm{CO}), 32\left(\mathrm{O}_{2}\right.$ and $\left.\mathrm{S}\right)$, 33 (HS), $34\left(\mathrm{H}_{2} \mathrm{~S}\right), 40(\mathrm{Ar}), 44\left(\mathrm{CO}_{2}\right), 48$ (SO), 60 (COS), $64\left(\mathrm{SO}_{2}\right) 65\left(\mathrm{HSO}_{2}\right)$ and $80\left(\mathrm{SO}_{3}\right)$. All experiments were performed with fresh samples using a total gas flow of 100 $\mathrm{ml} / \mathrm{min}$ and $\mathrm{Ar}$ as balance.

\subsubsection{Temperature programmed reaction experiments}

Prior to the TPReaction experiment, the sample was conditioned in a reaction mixture consisting of $0.05 \% \mathrm{CH}_{4}$ and $8 \% \mathrm{O}_{2}$ at $450^{\circ} \mathrm{C}$ for $60 \mathrm{~min}$. Subsequently, the temperature was decreased linearly with $5^{\circ} \mathrm{C} / \mathrm{min}$ from 450 to $100^{\circ} \mathrm{C}$, dwelled for $20 \mathrm{~min}$ and then increased to $450^{\circ} \mathrm{C}$ and dwelled for another $20 \mathrm{~min}$. This cooling-heating cycle was repeated subsequently with the addition of $40 \mathrm{ppm} \mathrm{SO}_{2}$ to the feed gas. An IR spectrum was recorded at each dwell step. During the temperature ramps three IR spectra per minute were recorded.

\subsubsection{Transient $\mathrm{SO}_{2}$ exposure experiments}

In the transient $\mathrm{SO}_{2}$ exposure experiments, the sample temperature was increased linearly with $5^{\circ} \mathrm{C} / \mathrm{min}$ from 20 to $450^{\circ} \mathrm{C}$ in a reaction mixture containing $0.05 \% \mathrm{CH}_{4}$ and $8 \% \mathrm{O}_{2}$. After exposing the sample to the reaction mixture for $60 \mathrm{~min}$ at $450^{\circ} \mathrm{C}$, the first $\mathrm{SO}_{2}$ exposure $\left(40 \mathrm{ppm} \mathrm{SO}_{2}\right.$ 
for $10 \mathrm{~s}$ ) was introduced. The duration of the following five $\mathrm{SO}_{2}$ exposures was $5 \mathrm{~min}$ and the intermittent sulfur-free periods were $20 \mathrm{~min}$. An IR spectrum was recorded in the reaction mixture 5 min prior the first $\mathrm{SO}_{2}$ exposure. IR spectra were then recorded each second for the first two exposures and for the remaining exposures two spectra per minute were recorded.

\section{Results}

\subsection{Temperature programmed reaction experiments}

The results from the TPReaction experiments with $\mathrm{Pt} /$ ceria and ceria monolith samples are shown in Figure 1 and 2 , respectively. The figures display methane conversion versus temperature for successive cooling-heating cycles for oxidation of $0.05 \% \mathrm{CH}_{4}$ with $8 \% \mathrm{O}_{2}$ for fresh samples (cycle 1-3, A panels), in the presence of 20 ppm $\mathrm{SO}_{2}$ (cycle 4-6, B panels) and after $\mathrm{SO}_{2}$ exposure (cycle 7-9, C panels). From Figure 1 it is clear that fresh $\mathrm{Pt} /$ ceria samples show negligible methane conversion below $300^{\circ} \mathrm{C}$. For each cycle the methane conversion during the extinction and ignition processes overlap. However, comparing the extinction-ignition processes for cycle 1-3 it is clear that the $\mathrm{CH}_{4}$ conversion is shifted somewhat towards higher temperatures during time on stream. For example for cycle 1 the temperature for $10\left(\mathrm{~T}_{10}\right)$ and $50 \%\left(\mathrm{~T}_{50}\right)$ conversion are 335 and $415^{\circ} \mathrm{C}$, respectively, and the conversion at $500^{\circ} \mathrm{C}$ is $85 \%$ whereas for cycle 3 the corresponding values are $350,435^{\circ} \mathrm{C}$ and $83 \%$, respectively. Introduction of $\mathrm{SO}_{2}$ results in no obvious difference for the cooling ramp in cycle 4 as compared to the preceding cycle.

Contrarily, for the heating ramp, a clear shift of the methane conversion towards lower temperatures is seen in the presence of $\mathrm{SO}_{2}$. The conversion at $500^{\circ} \mathrm{C}$, however, remains roughly the same. For the remaining cycles with $\mathrm{SO}_{2}$ present (cycle 5 and 6), the methane conversion decreases primarily during the dwell time at $500^{\circ} \mathrm{C}$, for example for cycle 4 the conversion is $80 \%$ while for cycle 5 and 6 the corresponding values are 70 and $50 \%$, respectively. In contrast to the first three cycles, a clear extinction-ignition hysteresis is observed for cycle 4-6 at temperatures between 300 and $500^{\circ} \mathrm{C}$, where the methane conversion generally is higher for the heating ramps. Finally, for the last three cycles (7-9) after $\mathrm{SO}_{2}$ exposure, the conversion of methane is generally low and the conversion profile during cooling-heating is nearly the same for each cycle. For the corresponding TPReaction experiments with ceria samples (Figure 2), a minor methane conversion is observed above $450^{\circ} \mathrm{C}$ for cycle $1-3$. During the first cycle in the presence of $\mathrm{SO}_{2}$ (cycle 4) some methane conversion is still observed but during cycle 5 and 6 the conversion is negligible in the entire temperature interval. The conversion is not regained when $\mathrm{SO}_{2}$ is removed from the feed, i.e. cycle 7-9.

In Figure 3, the concentration of $\mathrm{SO}_{2}$ in the reactor outlet for the cycles 4-6 is shown for the $\mathrm{Pt} /$ ceria (A panel) and ceria (B panel) samples. Neither for the Pt/ceria nor ceria samples, $\mathrm{SO}_{2}$ can be detected during the first cycle with $\mathrm{SO}_{2}$. Moving to cycle 5, some $\mathrm{SO}_{2}$ can be observed below $200^{\circ} \mathrm{C}$ for the cooling ramp and a net release of $\mathrm{SO}_{2}$ between 100 and $200^{\circ} \mathrm{C}$ is seen for the heating ramp. A significant difference between the $\mathrm{Pt} /$ ceria and ceria samples is observed above $200^{\circ} \mathrm{C}$ during heating. The $\mathrm{SO}_{2}$ concentration diminish to zero at $300^{\circ} \mathrm{C}$ for the $\mathrm{Pt} /$ ceria sample while for the ceria sample the corresponding temperature is $350^{\circ} \mathrm{C}$. For the last cycle with $\mathrm{SO}_{2}$ (cycle 6) during cooling, $\mathrm{SO}_{2}$ is observed at temperatures below 300 and $350^{\circ} \mathrm{C}$ for $\mathrm{Pt} /$ ceria and ceria samples, respectively. For both samples a maximum in $\mathrm{SO}_{2}$ concentration is seen at around $200^{\circ} \mathrm{C}$. Below $200^{\circ} \mathrm{C}$, some $\mathrm{SO}_{2}$ is adsorbed on both samples. During the heating ramp, a clear maximum in $\mathrm{SO}_{2}$ concentration at around $120^{\circ} \mathrm{C}$ indicates a release of $\mathrm{SO}_{2}$. Again, above $200^{\circ} \mathrm{C}$, the $\mathrm{SO}_{2}$ concentration decreases more rapidly for the $\mathrm{Pt} /$ ceria samples as compared to the ceria samples. Finally, for cycle 7-9, which are performed without $\mathrm{SO}_{2}$ in the feed, no release of $\mathrm{SO}_{2}$ can be observed.

\subsubsection{Transient $\mathrm{SO}_{2}$ exposure experiments}

The results from the transient $\mathrm{SO}_{2}$ exposure experiments with $\mathrm{Pt} /$ ceria carried out at different temperatures, i.e., $300,350,400$ and $500^{\circ} \mathrm{C}$, are shown in Figure 4. Panel A displays the methane conversion during the transient $\mathrm{SO}_{2}$ exposure and panel B-E show the response in $\mathrm{SO}_{2}$ concentration in the reactor outlet for the respective temperature together with the corresponding concentration profile for the empty reactor. For all temperatures in this study, the methane conversion increases in the presence of $\mathrm{SO}_{2}$ although this effect is less pronounced over longer periods on stream. At $500^{\circ} \mathrm{C}$, the methane conversion decreases rapidly during the sulfur-free periods and the concentration of $\mathrm{SO}_{2}$ in the reactor outlet is minor during the entire experiment (panel B). In contrast, at $400^{\circ} \mathrm{C}$, the increase in $\mathrm{CH}_{4}$ conversion in the presence of $\mathrm{SO}_{2}$ is clearly more pronounced throughout the entire experiment and the decline in overall methane conversion is more slow. For the experiments performed at 350 and $300^{\circ} \mathrm{C}, \mathrm{SO}_{2}$ exposure results again in an increase in the methane conversion, however, in both cases the increased conversion remains also during the sulfur-free periods leading to an overall increase in $\mathrm{CH}_{4}$ conversion for the first part of the experiment. As a function of time on stream, however, the methane conversion declines to around the initial levels. For the experiments performed at 400,350 and $300^{\circ} \mathrm{C}, \mathrm{SO}_{2}$ is clearly detected for the last parts of the experiments ( $c f$. panels C-E). With decreasing temperature, the $\mathrm{SO}_{2}$ breakthrough occurs earlier and reaches higher concentration levels. The outlet $\mathrm{SO}_{2}$ concentration is in all cases lower than the feed concentration.

Figure 5 displays the outlet $\mathrm{CH}_{4}$ and $\mathrm{CO}_{2}$ concentrations during the first three $\mathrm{SO}_{2}$ exposures at $400^{\circ} \mathrm{C}$ in more detail. Also included in the figure is the outlet $\mathrm{SO}_{2}$ concentration for the empty reactor experiment. It is clear 
that introduction of $\mathrm{SO}_{2}$ results in an immediate decrease in outlet $\mathrm{CH}_{4}$ concentration with corresponding rapid increase in $\mathrm{CO}_{2}$ concentration, i.e., increase of the rate for total oxidation of methane. During the $\mathrm{SO}_{2}$ exposure, the methane concentration declines but as soon as the $\mathrm{SO}_{2}$ feed is stopped the $\mathrm{CH}_{4}$ concentration starts to increase. The outlet $\mathrm{CO}_{2}$ concentration exhibits the opposite trend throughout the transient experiment, increases when the $\mathrm{CH}_{4}$ concentration decreases and vice versa.

\subsection{In situ DRIFT spectroscopy measurements}

\subsubsection{Temperature programmed reaction experiments}

The results from the TPReaction experiment performed with the Pt/ceria sample are shown in Figure 6 together with a schematic description of the experiment (panel A). Figure $6 \mathrm{~B}$ displays $\mathrm{CH}_{4}$ conversion versus temperature in the absence and presence of $\mathrm{SO}_{2}$. For the fresh sample, the methane conversion is similar at all temperatures for the cooling and heating ramps. Upon $\mathrm{SO}_{2}$ introduction at $450^{\circ} \mathrm{C}$, the methane conversion increases immediately from 30 to $55 \%$, and during the following cooling ramp, the conversion remains higher than in the absence of $\mathrm{SO}_{2}$ for all temperatures above $300^{\circ} \mathrm{C}$. In the presence of $\mathrm{SO}_{2}$ an extinction-ignition hysteresis is observed at temperatures between $250-450^{\circ} \mathrm{C}$ where the methane conversion is higher during the heating ramp for all temperatures. The IR spectra collected during the experiment are shown in Figure $6 \mathrm{C}$ and the collection point for each spectrum is indicated with 1-5 in Figure 6A. Spectrum 1, 2 and 4 are all collected at $450^{\circ} \mathrm{C}$ but as can be seen in panel $\mathrm{C}$, the response signals for these spectra are different between 3000 and 1200 $\mathrm{cm}^{-1}$. For spectrum 1 and 2, collected before the temperature ramps in Ar and reaction mixture, respectively, the response signal is higher than for spectrum 4 , which is collected in reaction mixture after the ramps. The responses signal of spectrum 4 is close to the signal of spectrum 3 , which is collected at $100^{\circ} \mathrm{C}$ in reaction mixture. The lowest response signal is obtained for spectra 5 , which is collected at $100^{\circ} \mathrm{C}$ in the presence of $\mathrm{SO}_{2}, \mathrm{CH}_{4}$ and $\mathrm{O}_{2}$. In Figure 6D, spectra collected in the presence and absence of $\mathrm{SO}_{2}$ at the start and end points of each ramp, i.e. at 450 and $100^{\circ} \mathrm{C}$, are shown. The spectra are shown as the difference between the measured spectrum and spectrum 2 (cf. panel C). In Table 1, assignments of IR bands for formate, carbonate, carboxylate, sulfite and sulfate species on ceria are summarized together with their respective literature references. These assignments serve as a basis for the interpretations of the present results. Spectrum a in panel $\mathrm{D}$ is collected when the first cooling ramp in the absence of $\mathrm{SO}_{2}$ starts and the spectrum has not changed compared to the spectrum 2 as indicated by the lack of absorption bands. Between 450 and $400^{\circ} \mathrm{C}$, sharp absorption bands appear in the carbonate/carboxylate region of the spectrum (1543, 1523, 1370, 1350, 1223 and $\left.1035 \mathrm{~cm}^{-1}\right)$. The intensity of these bands increases during the cooling ramp but not at the same rate indicating that there are different $\mathrm{CO}_{x}$ species present. At $350^{\circ} \mathrm{C}$, additional absorption bands appear at 2930, 2845, 1604 (broad), 1474 (broad) $\mathrm{cm}^{-1}$. According to references listed in Table 1, formation of bands at 2930 and $2845 \mathrm{~cm}^{-1}$ indicates that formate species are formed on the sample surface. The broad bands at 1604 and 1474 are likely associated with $\mathrm{CO}$ and/or OCO vibrations of formate, carbonate or carboxylate species. All bands that appear during the cooling ramp are present at $100^{\circ} \mathrm{C}$ and can therefore be seen in Figure 6D, spectrum b. During the dwell time at $100^{\circ} \mathrm{C}$, the intensity of the broad band at $1604 \mathrm{~cm}^{-1}$ increases slightly, which can be seen by comparing spectra $\mathrm{b}$ and $\mathrm{c}$ in Figure 6D. The intensity of the other bands remains constant. During the following heating ramp, the intensity of all bands decreases. The absorption bands at 2930, 2845, 1604 and $1474 \mathrm{~cm}^{-1}$ are not visible above $350^{\circ} \mathrm{C}$ and the bands at $1543,1370,1350$ and $1035 \mathrm{~cm}^{-1}$ disappear between 400 and $450^{\circ} \mathrm{C}$. At $450^{\circ} \mathrm{C}$, only two weak absorption bands at 1523 and $1223 \mathrm{~cm}^{-1}$ remain ( $c f$. spectrum d). When $\mathrm{SO}_{2}$ is introduced, new absorption bands at 1344, 1177, 1099, $1071 \mathrm{~cm}^{-1}$ appear immediately. According to the literature, the bands at 1344 and $1177 \mathrm{~cm}^{-1}$ are assigned to surface and bulk sulfates, respectively, while the bands at 1099 and $1071 \mathrm{~cm}^{-1}$ likely are connected to sulfite and/or hydrogensulfite species ( $c f$. Table 1). Upon $\mathrm{SO}_{2}$ introduction, some remaining $\mathrm{CO}_{x}$ species instantaneously disappear as indicated by the negative band at $1520 \mathrm{~cm}^{-1}$. After $4 \mathrm{~min}$ of $\mathrm{SO}_{2}$ exposure at $450^{\circ} \mathrm{C}$ a sharp band around $2127 \mathrm{~cm}^{-1}$ appears. This band has previously been attributed either to an electronic transition in $\mathrm{Ce}^{3+}[26,27]$ or to $\mathrm{CO}$ on $\mathrm{Ce}^{3+}[27]$.

Spectrum e in Figure 6D is collected by the time when the second cooling ramp starts, $27 \mathrm{~min}$ after the $\mathrm{SO}_{2}$ introduction. By this time the band at $2127 \mathrm{~cm}^{-1}$ has shifted to $2136 \mathrm{~cm}^{-1}$, the band at 1344 to $1360 \mathrm{~cm}^{-1}$ and the band at 1177 to $1184 \mathrm{~cm}^{-1}$. Additionally a broad band at $1613 \mathrm{~cm}^{-1}$ has appeared. During the cooling ramp, bands at 1391,1317 and $1231 \mathrm{~cm}^{-1}$ appear. The bands at 1391 and $1231 \mathrm{~cm}^{-1}$ are likely connected to surface and bulk sulfates, respectively, while the band at $1317 \mathrm{~cm}^{-1}$ indicates that $\mathrm{SO}_{2}$ is physisorbed [23]. Except for the band at 1360 $\mathrm{cm}^{-1}$, the intensity of all bands increase during cooling and the bands at 2136, 1360 and $1317 \mathrm{~cm}^{-1}$ are slightly blueshifted. At $100^{\circ} \mathrm{C}$, absorption bands are observed at 2142 , 1613, 1391, 1364, 1324, 1231, 1184, 1099 and $1071 \mathrm{~cm}^{-1}$ (cf. spectra $\mathrm{f}$ ). During the $20 \mathrm{~min}$ dwell time at $100^{\circ} \mathrm{C}$, the intensity of the $1391 \mathrm{~cm}^{-1}$ band decreases slightly, the band at $1324 \mathrm{~cm}^{-1}$ increases slightly and the other bands remain unchanged ( $c f$. spectrum g). During the subsequent heating ramp, the intensity of the 2142 and $1613 \mathrm{~cm}^{-1}$ bands decreases and the band at $1391 \mathrm{~cm}^{-1}$ disappears. On the other hand, the intensity of the bulk sulfate bands at 1231 and $1184 \mathrm{~cm}^{-1}$ increases significantly ( $c f$. spectrum h). 


\subsubsection{Transient $\mathrm{SO}_{2}$ exposure experiments}

The conversion of methane over the $\mathrm{Pt} /$ ceria powder sample during the transient $\mathrm{SO}_{2}$ exposure at $450^{\circ} \mathrm{C}$ is shown in Figure 7A. The shaded area represents the period when $\mathrm{SO}_{2}$ is added to the reaction feed. The first $\mathrm{SO}_{2}$ exposure continued for $10 \mathrm{~s}$ while each of the following for $5 \mathrm{~min}$. Consistent with the transient $\mathrm{SO}_{2}$ exposure experiments carried out in the flow reactor, the methane conversion increases when $\mathrm{SO}_{2}$ is introduced and decreases when $\mathrm{SO}_{2}$ is removed from the feed. The corresponding change in the Gram-Schmidt signal, i.e. total intensity of the region 900$4000 \mathrm{~cm}^{-1}$, is shown in Figure 7B. During the first $\mathrm{SO}_{2}$ exposure, the total absorption increases rapidly but for the sulfur-free period the change is negligible. Upon next $\mathrm{SO}_{2}$ exposure, the Gram-Schmidt signal increases first rapidly and then more slowly during the $\mathrm{SO}_{2}$ exposure and remains constant for the following sulfur-free period. This trend is repeated for the last four exposure periods, although, the Gram-Schmidt signal increases less upon each exposure and finally a steady state is most likely reached.

In Figure 8, IR spectra collected at the end of the first, second and sixth $\mathrm{SO}_{2}$ exposure are shown along with each spectra collected at the end of the subsequent 20 min sulfurfree period. Immediately upon $\mathrm{SO}_{2}$ introduction, sulfate and sulfite species are formed on ceria which is indicated by the absorption bands at 1345,1180 and $1083 \mathrm{~cm}^{-1}$ for the spectrum collected after the first $\mathrm{SO}_{2}$ exposure (spectrum a, solid line). The negative band at $1517 \mathrm{~cm}^{-1}$ indicates that carbonate and/or carboxylate species are removed when $\mathrm{SO}_{2}$ is introduced. During the subsequent sulfur-free period, the intensity of all ad- $\mathrm{SO}_{x}$ bands increases, which is illustrated by the spectrum collected at the end of the first sulfur-free period (spectrum a, dashed line). This observation is not consistent with the constant Gram-Schmidt signal, which is obtained during the same time period ( $c f$. Figure 7B). However, the change observed between solid and dashed lines in spectra a occurs during the first 15 seconds after the $\mathrm{SO}_{2}$ feed is stopped. During the second $\mathrm{SO}_{2}$ exposure, the intensity of the bands at 1345,1180 and $1083 \mathrm{~cm}^{-1}$ increases further but, as can be seen in spectra $b$, the intensity remains constant during the second sulfur-free period. The same trend is repeated also for the following four $\mathrm{SO}_{2}$ exposures, the intensity of ad- $\mathrm{SO}_{x}$ bands increases during the $\mathrm{SO}_{2}$ exposure and remains constant during the sulfurfree period. However, upon further $\mathrm{SO}_{2}$ exposure, the band at 1345 shifts to $1357 \mathrm{~cm}^{-1}$ and the band at 1083 to 1087 $\mathrm{cm}^{-1}$. During the third $\mathrm{SO}_{2}$ exposure, a new absorption band at $2135 \mathrm{~cm}^{-1}$ appears and increases upon further $\mathrm{SO}_{2}$ exposure ( $c f$. spectra $c$ in Figure 8 ). The same band was also observed during the TPReaction experiments and is previously assigned to reduced ceria [26,27].

\section{Discussion}

The present results show that $\mathrm{SO}_{2}$ can promote the total oxidation of methane over $\mathrm{Pt} /$ ceria catalysts under oxygen excess conditions, specifically this was observed for temperatures between 300 and $450^{\circ} \mathrm{C}$. The promoting effect is clearly demonstrated by the lower $\mathrm{T}_{50}$ for methane oxidation observed in the TPReaction experiments ( $c f$. Figure 1 and 6) as well as the instantaneous increase in methane conversion achieved during the transient $\mathrm{SO}_{2}$ exposure experiments ( $c f$. Figure 4, 5 and 7 ). As a function of time on stream, however, the observed promoting effect diminish and instead the methane oxidation becomes inhibited. The forthcoming discussion is thus focused on interpretation and explanation of the results as to increase the understanding of both the promoting and inhibiting effects of $\mathrm{SO}_{2}$ on methane oxidation over $\mathrm{Pt} /$ ceria.

It is well known that the activity for methane oxidation over supported noble metals is highly dependent on the oxygen concentration [2,6-10]. For platinum catalysts, the metal surface becomes self-poisoned by oxygen at low temperatures under lean reaction conditions and consequently, the rate-limiting step is the dissociative adsorption of methane. The promoting effect in the presence of $\mathrm{SO}_{2}$ in the present study is most likely connected to an increased number of adsorption sites for dissociative adsorption of methane, by breakage of the oxygen self-poisoning and/or by formation of a new type of active site. $\mathrm{As}_{\mathrm{SO}_{2}}$ has a higher sticking coefficient on platinum than $\mathrm{O}_{2}[28,29], \mathrm{SO}_{2}$ competes with oxygen for surface sites. If the temperature is sufficiently high, oxidation of $\mathrm{SO}_{2}$ will occur when both $\mathrm{SO}_{2}$ and oxygen are present on the platinum surface and, thus, surface oxygen will be consumed. For the Pt/ceria sample, only negligible amounts of $\mathrm{SO}_{2}$ are detected above $300^{\circ} \mathrm{C}$ ( $c f$. Figure $3 \mathrm{~A}$ ) and accordingly $\mathrm{SO}_{2}$ either remains as ad- $\mathrm{SO}_{x}$ species on the catalyst surface or is oxidized to gaseous $\mathrm{SO}_{3}$. Although simultaneous detection of $\mathrm{SO}_{2}$ and $\mathrm{SO}_{3}$ is not straightforward with the experimental setup used here, it is clear that the decrease in outlet $\mathrm{SO}_{2}$ concentration is correlated with the increase in activity for methane oxidation since it is also above $300^{\circ} \mathrm{C}$ the promotional effect is observed in the TPReaction experiments. However, the $\mathrm{SO}_{2}$ promotion cannot solely be explained by oxidation of $\mathrm{SO}_{2}$ to gaseous $\mathrm{SO}_{3}$ over $\mathrm{Pt}$ and thereby removal of surface oxygen. The absence of a promotional effect of $\mathrm{SO}_{2}$ in the extinction ramp for the TPReaction experiments in Figure 1 indicates that there are additional conditions that have to be fulfilled for the promotion to occur.

It has previously been reported that the support material has an important role in the mechanism for $\mathrm{SO}_{2}$ promotion on hydrocarbon oxidation. Hubbard et al. [15], Burch et al. [16] and Skoglundh et al. [17] have reported a promotional effect on propane oxidation over $\mathrm{Pt} / \mathrm{Al}_{2} \mathrm{O}_{3}$ but not over $\mathrm{Pt} / \mathrm{SiO}_{2}$ when $\mathrm{SO}_{2}$ was introduced. It is well known that sulfur oxides interact differently with these support materials, while rapidly forming surface sulfates on $\mathrm{Al}_{2} \mathrm{O}_{3}$ such species are not formed in the same extent on the $\mathrm{SiO}_{2}$ surface $[17,30]$. For the Pt/ceria sample, the DRIFTS results reported in Figure $7 \mathrm{~B}$ and 8 show that sulfate species are formed on ceria immediately upon $\mathrm{SO}_{2}$ introduction. 
The sulfate formation is accompanied by an instantaneous increase in the methane conversion ( $c f$. Figure 7A). However, it is not likely that $\mathrm{SO}_{x}$ adsorption leads to formation of new active sites on the support material itself since $\mathrm{SO}_{2}$ inhibits the methane oxidation reaction over the bare ceria sample ( $c f$. Figure 2). The role of the support might be to provide an additional pathway for removal of $\mathrm{SO}_{x}$ from $\mathrm{Pt}$ via $\mathrm{SO}_{x}$ spillover to nearby sites on the support, i. e., not only desorption of $\mathrm{SO}_{x}$ into the gas phase, so that more metallic Pt sites will be available for methane adsorption. For the transient sulfur exposure experiments performed at 300 and $350^{\circ} \mathrm{C}$ ( $c f$. Figure 4 and 5), the methane conversion starts to decrease when $\mathrm{SO}_{2}$ is removed from the feed but not to the initial conversion of the experiment, indicating that the role of the support is not only to provide an alternative route for $\mathrm{SO}_{x}$ removal from $\mathrm{Pt}$.

It has been reported that sulfation of alumina increases the surface acidity $[15,16]$. However, Hubbard et al. [15] did not find any correlation between surface acidity and catalytic activity for sulfated $\mathrm{Pt} / \mathrm{SiO}_{2}, \mathrm{Pt} / \mathrm{ZrO}_{2}$ and $\mathrm{Pt} / \mathrm{Al}_{2} \mathrm{O}_{3}$. For the former two samples, the activity for propane oxidation remained unchanged upon $\mathrm{SO}_{2}$ addition while for the latter the activity increased significantly. For the sulfur exposed supports however, the increase in surface acid strength as measured by Hammett indicators was highest for $\mathrm{ZrO}_{2}$, moderate for $\mathrm{Al}_{2} \mathrm{O}_{3}$ and insignificant for $\mathrm{SiO}_{2}$. Burch et al. [16] have reported that the acidity of the $\mathrm{Pt} / \mathrm{Al}_{2} \mathrm{O}_{3}$ support, as measured by $\mathrm{NH}_{3}$-TPD, increases linearly with time of sulfation but the activity for propane oxidation does not follow the same trend. The authors proposed that sulfation of $\mathrm{Al}_{2} \mathrm{O}_{3}$ sites close to $\mathrm{Pt}$ are important for propane activation while all sulfates contribute to surface acidity. Sulfates close to platinum would withdraw electron density from the metal, forming sites composed by cooperative pairs of $\mathrm{Pt}^{\delta+}$ and $\left(\mathrm{SO}_{4}\right)^{\delta-}$ species that more efficiently can activate $\mathrm{CH}_{4}$ for dissociation through polarization of the $\mathrm{C}-\mathrm{H}$ bond. The transient $\mathrm{SO}_{2}$ exposure experiments performed in the DRIFTS cell indicate that sulfation of certain sites on the ceria support influences the methane oxidation more than others. The slope of the Gram-Schmidt signal, i.e., the total peak area, shown in Figure 7B can be used as a measure of the formation rate of ad- $\mathrm{SO}_{x}$ species on the catalyst surface. The immediate increase in methane conversion ( $c f$. Figure 7A) and the corresponding rapid increase in peak area upon $\mathrm{SO}_{2}$ introduction indicates an initial high number of adsorption sites easily accessible for $\mathrm{SO}_{x}$ species, most likely sites on ceria close to Pt. During the $\mathrm{SO}_{2}$ exposure, these sites are gradually occupied which is shown by the change in slope of the total intensity signal. For the sulfur-free period, the activity for methane oxidation decreases ( $c f$. Figure 7A) while the type and amount of sulfates do not vary significantly ( $c f$. Figure $7 \mathrm{~B}$ and 8 ). However, upon next introduction of $\mathrm{SO}_{2}$, both the catalytic activity and the total peak area increase rapidly again. These results indicate that a rearrangement of surface species occurs during the sulfur-free period such that some of the easily accessible adsorption sites for $\mathrm{SO}_{x}$ are reexposed. It is likely that these are important for the promotional effect.

However, not only the type of support material seems to be important in order to obtain the promotional effect on methane oxidation by $\mathrm{SO}_{2}$ addition. The sample history, or most likely the surface composition of the support material, plays an important role. As can be seen in Figure 1, the promotional effect observed during the heating ramp is absent for the corresponding cooling ramp in the TPReaction experiment. Further, the promotional effect of $\mathrm{SO}_{2}$ on methane oxidation at $450^{\circ} \mathrm{C}$ in the DRIFTS cell may vary depending on the pretreatment. For a sample heated in pure argon flow and thereafter exposed to the reaction condition for one hour at $450^{\circ} \mathrm{C}$, the change in activity upon $\mathrm{SO}_{2}$ introduction is minor (results not shown here). If the sample instead is heated in the reaction mixture, a promoting effect is observed ( $c f$. Figure 7 ). The most pronounced increase in activity is observed after the first ramp in the TPReaction experiment when $\mathrm{SO}_{2}$ is introduced 20 min after reaching $450^{\circ} \mathrm{C}$ ( $c f$. Figure 6). For all FTIR experiments the same type of ad- $\mathrm{SO}_{x}$ absorption bands are observed in the region between 1000 and $1400 \mathrm{~cm}^{-1}$ when $\mathrm{SO}_{2}$ is introduced. However, the negative carbonate band around $1520 \mathrm{~cm}^{-1}$ is only observed for the experiments where a promotional effect is obtained. Additionally, as can be seen in Figure 6B, the change of the sample which makes it susceptible for $\mathrm{SO}_{2}$ promotion does not influence the activity for methane oxidation during the TPReaction experiments. No hysteresis is observed for the extinction and ignition processes in the absence of $\mathrm{SO}_{2}$, which indicates that the temperature treatment does not change the number and/or type of active sites, probably platinum sites. Therefore, it is likely that the change of the catalyst sample during the temperature ramps is due to the ceria. It has previously been suggested that oxygen deficient ceria may delay oxidation of platinum when changing from netreducing to netoxidizing conditions [11]. Ceria is well-known to store and release oxygen due to the ability of cerium to easily change oxidation state between $\mathrm{Ce}^{4+}$ and $\mathrm{Ce}^{3+}$. While total reduction of bulk $\mathrm{CeO}_{2}$ requires high temperature to occur, the redox potential of the surface region is higher [31,32]. Moreover, Pt has been shown to govern such redox processes [31-33] by facilitating oxygen transport, i.e., spillover and reversed spillover $[33,34]$. The DRIFTS results obtained in this study indicate that adsorption of both carbon and sulfur containing species will partially reduce ceria. The difference in IR absorption found in Figure 6C, comparing spectrum 2 and 4 collected under the same conditions but before and after the temperature ramp, could be due to a change in the oxidation state of ceria. Ceria is an n-type semiconductor in its reduced form, and due to the increased number of conducting electrons the IR absorption can increase as compared to the oxidized state [27]. During the temperature ramp in the absence of $\mathrm{SO}_{2}, \mathrm{C}-\mathrm{H}$ absorption bands $(2930$ and $2850 \mathrm{~cm}^{-1}$ ) are observed below $300^{\circ} \mathrm{C}$ and it is possible that the catalyst surface is not completely reoxidized while heating before the last spectrum is collected. Removal 
of surface carbonates, as represented by the negative band around $1520 \mathrm{~cm}^{-1}$, indicates the presence of remaining carbon species on the support when $\mathrm{SO}_{2}$ is introduced. Another indication of ceria reduction is the absorption band around 2127-2142 $\mathrm{cm}^{-1}$ formed during methane oxidation in the presence of $\mathrm{SO}_{2}$. Electronic transitions in $\mathrm{Ce}^{3+}$ could give rise to absorption in this range $[27,26]$.

Ceria in slightly reduced state is able to withdraw oxygen from platinum and thereby increase the number of available sites for dissociative adsorption of methane. Therefore, it is likely that partially reduced ceria sites close to platinum have a higher tendency to withdraw oxygen from platinum than sites more far away, i.e. that the promotional effect obtained by $\mathrm{SO}_{2}$ on the activity for methane oxidation is dependent on which sites that are sulfated. We have previously shown that platinum facilitates sulfate formation on ceria at $250^{\circ} \mathrm{C}[24,25]$ but in the work by Bazin et al. [35] no influence of $\mathrm{Pt}$ was observed at $400^{\circ} \mathrm{C}$. Therefore, it is likely that sulfates may form on surface sites close to Pt to a higher extent at low temperatures while evenly distributed over the surface at higher temperatures. The tendency to form sulfates on different sites depending on the temperature may be important for the explanation of the extinction-ignition hysteresis in methane oxidation over $\mathrm{Pt} /$ ceria in the presence of $\mathrm{SO}_{2}$. However, ceria oxidation may also proceed via different mechanisms depending on temperature. At this point it is difficult to distinguish which of these parameters that is most important but it is likely that both contribute to the hysteresis. At the highest temperature in the study, i.e. $500^{\circ} \mathrm{C}$, ad- $\mathrm{SO}_{x}$ species are rapidly formed all over the support and ceria is partly reduced in the sulfate formation process. However, at this temperature it is likely that oxidation of ceria proceeds mainly with oxygen from the gas phase. For the cooling ramp, the experiment starts with a highly dynamic system in terms of oxygen transport and sulfate formation. For the heating ramp on the other hand, the experiment starts from a state where the surface is covered by loosely bound sulfur species, which will form sulfates when the temperature is sufficiently high. Sulfate formation is facilitated by platinum at low temperature and therefore, sulfates may preferably form on ceria sites close to platinum during the heating ramp. Sulfate formation will partially reduce the ceria, forming oxygen vacancies. Since platinum is known to increase the oxygen storage dynamics of ceria, spillover of atomic oxygen from platinum is likely important for ceria reoxidation at low temperature. This process will withdraw oxygen from platinum and thereby facilitate the dissociative adsorption of methane on $\mathrm{Pt}$.

However, for the $\mathrm{Pt} /$ ceria samples used in this study there is not only a promotional effect obtained by the introduction of $\mathrm{SO}_{2}$. All activity studies in the flow reactor show an inhibiting effect from long-time $\mathrm{SO}_{2}$ exposure. During the TPReaction experiments the degradation is most pronounced at $500^{\circ} \mathrm{C}$ but from the transient sulfur exposure experiments an inhibiting effect is observed also at lower temperatures. However, the poisoning pro- cess appears to be slower at low temperature. Since $\mathrm{SO}_{2}$ inhibits the methane oxidation over pure ceria, it is likely that sulfate formation on ceria influences the oxygen mobility within the material. As discussed above, the ability of partially reduced ceria to withdraw oxygen from platinum is most likely important for the relatively high activity for methane oxidation, which is found for the $\mathrm{Pt} /$ ceria catalysts. If sulfate formation on ceria significantly reduces the oxygen mobility the benefits with ceria as support material are significantly lowered. From Figure 1 it is clear that the inhibiting effect of $\mathrm{SO}_{2}$ is irreversible since the $\mathrm{Pt} /$ ceria catalyst regains no activity when $\mathrm{SO}_{2}$ is removed from the feed. The results from the TPReaction experiments also indicate that the poisoning effect is closely related to the presence of $\mathrm{SO}_{2}$. When $\mathrm{SO}_{2}$ is removed from the feed, the degradation process stops and the catalyst remains stable but significantly less active than before $\mathrm{SO}_{2}$ exposure. We have previously reported that cerium sulfates are stable under lean conditions at temperatures below $500^{\circ} \mathrm{C}[24]$. Therefore, it is not surprising that no sulfur species desorb when $\mathrm{SO}_{2}$ is excluded in the feed and that the activity for methane oxidation is not regained. The rate of sulfate formation could most likely be correlated to the poisoning rate of the catalyst. The rate of sulfate formation on $\mathrm{Pt} /$ ceria is higher at 400 than at $250^{\circ} \mathrm{C}$ [24] and as can be seen in Figure 4, the poisoning appears to proceed faster at higher temperature.

In summary, the ability of slightly reduced ceria to withdraw oxygen from $\mathrm{Pt}$ is likely beneficial for the total oxidation of methane. Due to the redox properties of ceria, incoming species like methane and $\mathrm{SO}_{2}$ can be oxidized on the ceria surface forming oxygen vacancies in the support. Since platinum is known to facilitate oxygen storage in ceria, it is likely that reoxidation of ceria will consume oxygen from the platinum surface and thereby expose sites for dissociative adsorption of methane. We suggest that the promotion of the activity for methane oxidation obtained by exposing $\mathrm{Pt} /$ ceria catalysts to $\mathrm{SO}_{2}$ can be explained by the rapid sulfate formation rate on ceria between 300 and $500^{\circ} \mathrm{C}$. However, ceria sulfates are stable below $500^{\circ} \mathrm{C}$ in oxygen excess [24] and eventually, by continuous sulfur exposure, ceria will be saturated by sulfates and the oxygen dynamics in the system settles. The results from this study indicate that the $\mathrm{Pt} /$ ceria system might be too dynamic to permanently increase the activity for methane oxidation over Pt/ceria catalysts by sulfur addition. However, it is conceivable that periodic regeneration in analogy with regeneration of $\mathrm{NO}_{x}$ traps can be utilized also for these catalysts.

\section{Concluding Remarks}

The influence of sulfur dioxide on methane oxidation over $\mathrm{Pt} / \mathrm{CeO}_{2}$ catalysts has been studied under lean conditions by transient flow reactor and in situ Fourier transform infrared spectroscopy experiments. The results show 
that sulfur dioxide can promote the oxidation of methane at $300-450^{\circ} \mathrm{C}$, although as a function of time on stream the promoting effect diminish and instead the methane oxidation becomes inhibited. The spectroscopic data show that introduction of $\mathrm{SO}_{2}$ results in an immediate formation of sulfate species on ceria that is accompanied by a corresponding instantaneous increase in methane conversion. Sulfate formation on ceria sites close to platinum can electronically modify the platinum sites and/or form new sites in the metal-support interface which can polarize the $\mathrm{C}-\mathrm{H}$ bond and, thus, facilitate methane dissociation. Furthermore, the spectroscopic analysis shows that despite the lean conditions, upon $\mathrm{SO}_{2}$ exposure, the ceria is reduced indicating that oxidation of ceria with gas phase oxygen is kinetically hindered. Dissociative adsorption of oxygen on platinum, however, can facilitate ceria oxidation via a spillover mechanism. This process will likely decrease the oxygen coverage and/or induce rearrangement of adsorbates on the platinum surface and, thereby, facilitating the dissociative adsorption of methane and subsequent oxidation. Eventually the ceria becomes saturated with sulfates and the oxygen dynamics in the platinum-ceria system settles. As a consequence, the system regresses towards highly oxidized platinum and/or otherwise active sites on the ceria or platinum-ceria boundary becomes blocked, which may explain the long-term inhibiting effect by $\mathrm{SO}_{2}$ exposure.

\section{Acknowledgments}

This work has been performed within the INGAS-project which is financially supported by the European Comission FP7 Programme (Proj. no. 218447) and partly within the Competence Centre for Catalysis, which is hosted by Chalmers University of Technology and financially supported by the Swedish Energy Agency and the member companies AB Volvo, Volvo Car Corporation AB, Scania CV AB, Saab Automobile Powertrain AB, Haldor Topsøe A/S, and ECAPS AB. Financial support from Knut and Alice Wallenberg Foundation, Dnr KAW 2005.0055, is greatfully acknowledged.

\section{References}

[1] D. Ciuparu, M. R. Lyubovsky, E. Altman, L. D. Pfefferle and A. Datye, Catal. Rev. 44 (2002) 593

[2] R. Burch, P. K. Loader and F. J. Urbano, Catal. Today 27 (1996) 243.

[3] J. K. Lampert, M. S. Kazi and R. J. Farrauto, Appl. Catal. B: Environ. 14 (1997) 211.

[4] P. Gélin, L. Urfels, M. Primet and E. Tena, Catal. Today 83 (2003) 45.

[5] L. J. Hoyos, H. Praliaud and M. Primet Appl. Catal. A: General 98 (1993) 125.

[6] P.-A. Carlsson, M. Nordström and M. Skoglundh, Top. Catal. 52 (2009) 1962.

[7] P.-A. Carlsson, E. Fridell, M. Skoglundh, Catal. Lett. 115(1-2) (2007) 1.
[8] E. Becker, P.-A. Carlsson, H. Grönbeck and M. Skoglundh, J. Catal. 252 (2007) 11.

[9] E. Becker, P.-A. Carlsson, L. Kylhammar, M. Newton and M. Skoglundh, J. Phys. Chem. C 115 (2010) 944.

[10] V. P. Zhdanov, P.-A. Carlsson, B. Kasemo, J. Chem. Phys. 126 (2007) 234705.

[11] E. Becker, P.-A. Carlsson and M. Skoglundh, Top. Catal. 52 (2009) 1957.

[12] P.-A. Carlsson and M. Skoglundh, Appl. Catal. B: Environ. 101 (2011) 669.

[13] G. Corro, C. Cano and J.L. Garcia Fierro, J. Mol. Catal. A: Chem. 281 (2008) 179.

[14] H.C. Yao, H.K. Stepien and H.S. Gandhi, J. Catal. 67 (1981) 231.

[15] C.P. Hubbard, K. Otto, H.S. Gandhi and K.Y.S. Ng, J. Catal. 144 (1993) 484.

[16] R. Burch, E. Halpin, M. Hayes, K. Ruth and J.A. Sullivan, Appl. Catal. B: Environ. 19 (1998) 199.

[17] M. Skoglundh, A. Ljungqvist, M. Petersson, E. Fridell, N. Cruise, O. Augustsson and E. Jobson, Appl. Catal. B: Environ. 30 (2001) 315.

[18] A. Hinz, M. Skoglundh, E. Fridell and A. Andersson, J. Catal. 201 (2001) 247.

[19] G. Corro, R. Montiel and C. Vázquez, Catal. Commun. 3 (2002) 533.

[20] V. Dupont, J.M. Jones, S-H. Zhang, A. Westwood and M.V. Twigg, Chem. Eng. Sci. 59 (2004) 17.

[21] K. Wilson, C. Hardacre and R.M. Lambert, J. Phys. Chem. 99 (1995) 13755

[22] L. Zhang, D. Weng, B. Wang and X. Wu, Catal. Commun. 11 (2010) 1229.

[23] M. Waqif, P. Bazin, O. Saur, J.C. Lavalley, G. Blanchard and O. Touret, Appl. Catal. B: Environ. 11 (1997) 193.

[24] L. Kylhammar, P.-A. Carlsson, H. H. Ingelsten, H. Grönbeck and M. Skoglundh, Appl. Catal. B: Environ. 84 (2008) 268.

[25] M. Happel, L. Kylhammar, P.-A. Carlsson, J. Libuda, H. Grönbeck and M. Skoglundh, Appl. Catal. B: Environ. 91 (2009) 679 .

[26] C. Binet, A. Badri and J.-C. Lavalley, J. Phys. Chem. 98 (1994) 6392.

[27] F. Bozon-Verduraz and A. Bensalem, J. Chem. Soc. Faraday Trans. 90 (1994) 653.

[28] St. Astegger and E. Bechtold, Surf. Sci. 122 (1982) 491.

[29] A.-P. Elg, F. Eisert and A. Rosén, Surf. Sci. 382 (1997) 57.

[30] E. Xu, K. Seshan and J.R.H. Ross, Appl. Catal. B: Environ. 11 (1996) 65.

[31] H. C. Yao and Y. F. Yu Yao, J. Catal. 86 (1984) 254.

[32] B. Harrison, A. F. Diwell and C. Hallett, Platinum Metals Rev. 32 (1988) 73.

[33] C. Li, Y. Chen, W. Li and Q. Xin, Stud. Surf. Sci. Catal. 77 (1993) 217.

[34] C. Li, Y. Song, Y. Chen, Q. Xin, X. Han and W. Li, Stud. Surf. Sci. Catal. 112 (1993) 439.

[35] P. Bazin, O. Saur, J.C. Lavalley, G. Blanchard, V. Visciglio and O. Touret, Appl. Catal. B: Environ. 13 (1997) 265.

[36] T. Shido and Y. Iwasawa, J. Catal. 136 (1992) 493.

[37] E. Odier, Y. Shuurman and C. Mirodatos, Catal. Today 127 (2007) 230

[38] C. Li, Y. Sakata, T. Arai, K. Domen, K-i. Maruya and T. Onishi, J. Chem. Soc. Faraday Trans. 85 (1989) 929.

[39] T. Luo and R.J. Gorte, Appl. Catal. B: Environ. 53 (2004) 77. 

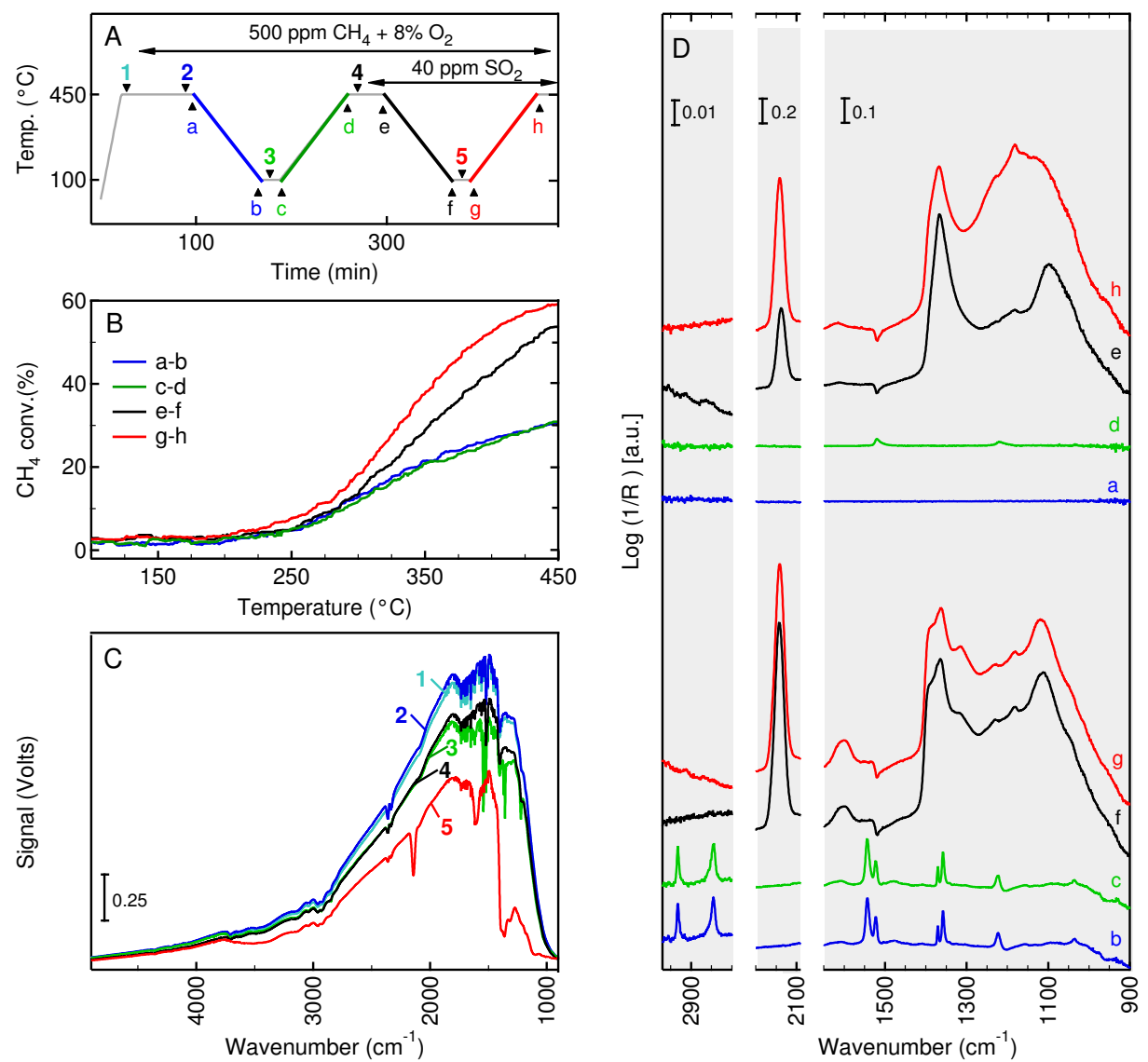

Fig. 6. Temperature programmed reaction experiments with $0.05 \% \mathrm{CH}_{4}$ and $8 \% \mathrm{O}_{2}$ in Ar over $\mathrm{Pt} /$ ceria powder sample (cycle 1 ) and in the presence of $40 \mathrm{ppm} \mathrm{SO} \mathrm{SO}_{2}$ (cycle 2). The cooling and heating ramp rate was $5^{\circ} \mathrm{C} / \mathrm{min}$. (A) Schematic description of the experiment with the collection points of IR spectra (1-5) and difference spectra (a-h) indicated. (B) Methane conversion during cooling/heating ramps for cycle 1 $(-/-)$ and cycle $2(-/-)$. (C) IR absorption spectra. (D) Difference spectra a, d, e and h were collected at $450^{\circ} \mathrm{C}$ and $\mathrm{b}, \mathrm{c}, \mathrm{f}$, and $\mathrm{g}$ at $100^{\circ} \mathrm{C}$. 
Table 1

Summary of infrared band positions for adsorbed carbon and sulfur oxygenates assigned in the open literature.

\begin{tabular}{|c|c|c|}
\hline Assignment & Infrared band position $\left(\mathrm{cm}^{-1}\right)$ & Reference \\
\hline Bridged formate & $1358,1569,2933$ & {$[36]$} \\
\hline \multirow[t]{2}{*}{ Bidentate formate } & $1358,1547,2845$ & {$[36]$} \\
\hline & 1378,1580 & {$[37]$} \\
\hline \multirow[t]{4}{*}{ Unidentate carbonate } & $1044,1370,1460$ & {$[36]$} \\
\hline & 1066,1456 & {$[37]$} \\
\hline & $854,1062,1348,1454$ & {$[38]$} \\
\hline & $850,1070,1360-1380,1460-1480$ & {$[27]$} \\
\hline \multirow[t]{4}{*}{ Bidentate carbonate } & $1028,1286,1570$ & {$[36]$} \\
\hline & 1028,1560 & {$[37]$} \\
\hline & $854,1028,1286,1562$ & {$[38]$} \\
\hline & $830-860,1030,1250-1310,1580-1610$ & {$[27]$} \\
\hline \multirow[t]{3}{*}{ Bridged carbonate } & 1015,1398 & {$[37]$} \\
\hline & $1132,1219,1396,1728$ & {$[38]$} \\
\hline & $1180,1700-1750$ & {$[27]$} \\
\hline Bulk carbonate & $880,1060,1350-1400,1420-1480$ & {$[27]$} \\
\hline \multirow[t]{3}{*}{ Inorganic carboxylate } & 1310,1510 & {$[36]$} \\
\hline & 1310,1510 & {$[38]$} \\
\hline & $1350-1400,1560-1580$ & {$[27]$} \\
\hline \multirow[t]{3}{*}{ Surface sulfate } & $1340-1400$ & {$[23]$} \\
\hline & $1345-1370$ & {$[39]$} \\
\hline & $1365-1390$ & {$[24]$} \\
\hline \multirow[t]{3}{*}{ Bulk sulfate } & $1140-1220$ & {$[23]$} \\
\hline & 1160 & {$[39]$} \\
\hline & $1175-1180,1215-1235$ & {$[24]$} \\
\hline \multirow[t]{2}{*}{ Sulfite/hydrogen sulfite } & $840,880,998,1040$ & {$[23]$} \\
\hline & 980,1220 & [39] \\
\hline
\end{tabular}

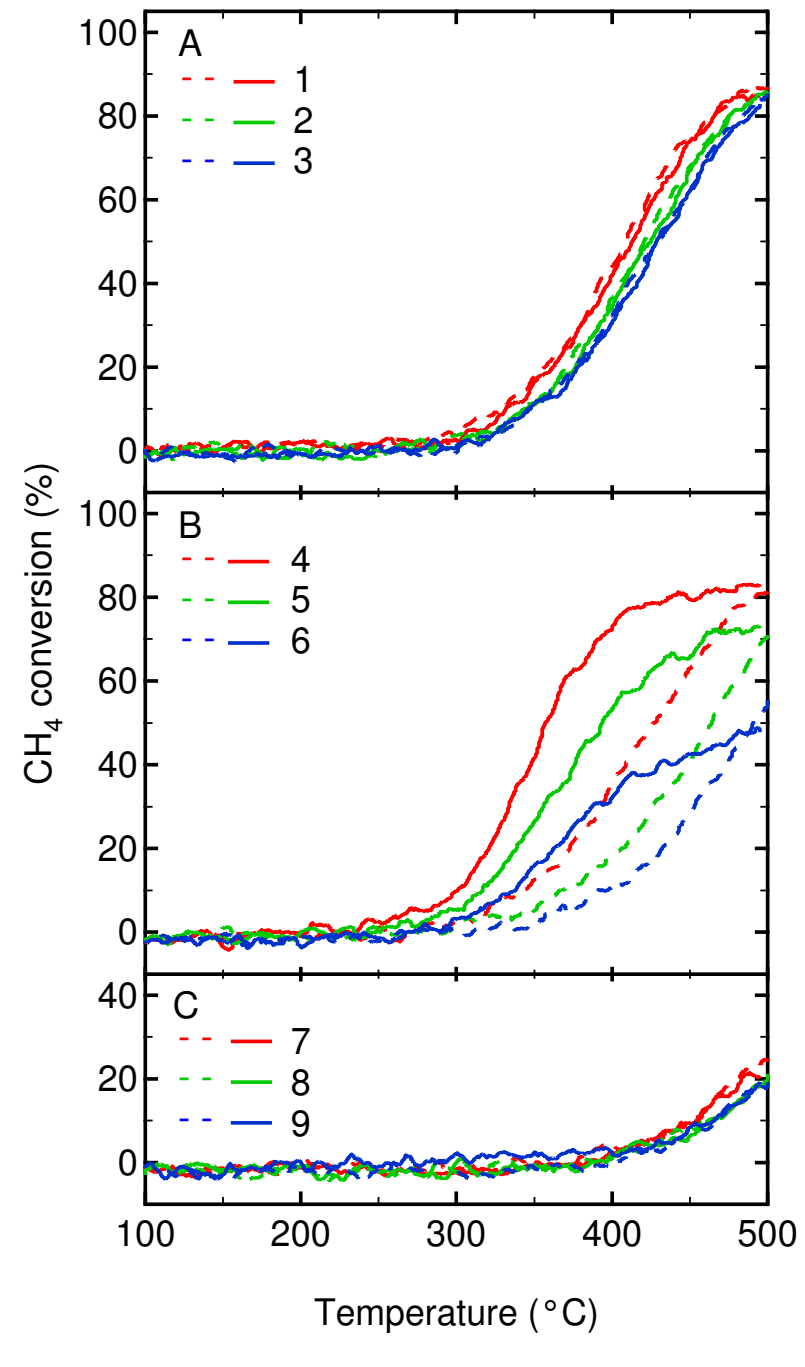

Fig. 1. Temperature programmed reaction experiments with $0.05 \%$ $\mathrm{CH}_{4}$ and $8 \% \mathrm{O}_{2}$ in Ar over fresh Pt/ceria samples (panel A), with an additional of 20 ppm $\mathrm{SO}_{2}$ present (panel B) and after $\mathrm{SO}_{2}$ exposure (panel $\mathrm{C}$ ). The ramp rate for both cooling (dashed) and heating (solid) was $5^{\circ} \mathrm{C} / \mathrm{min}$. The consecutive cycle numbers are marked. 


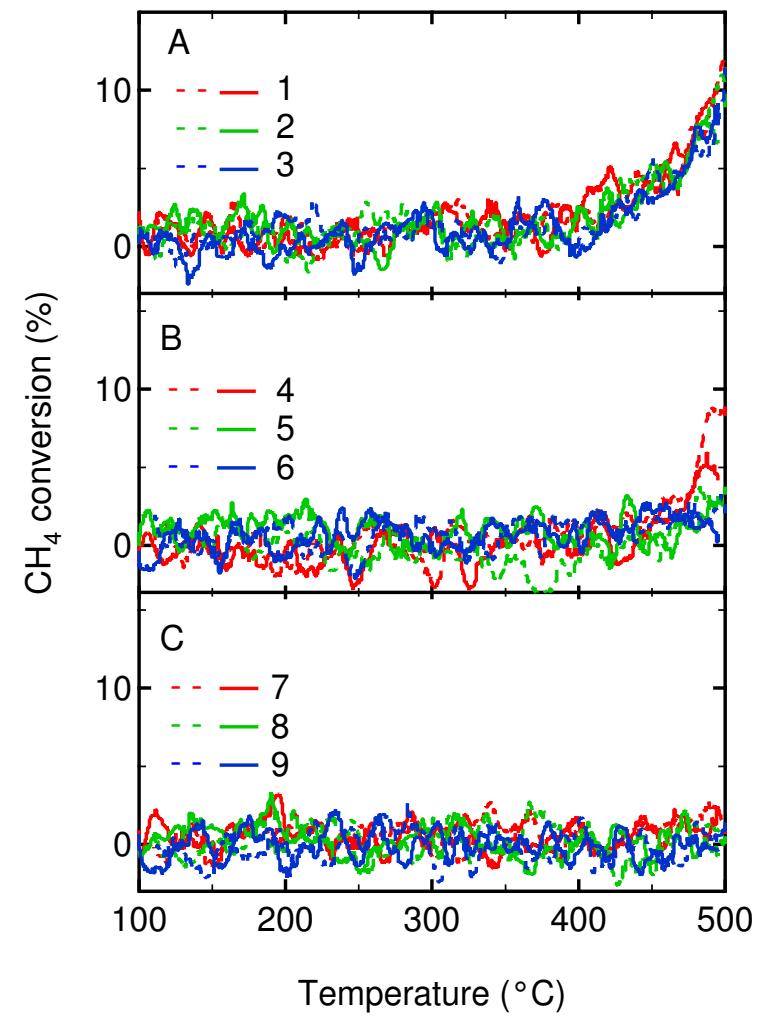

Fig. 2. Temperature programmed reaction experiments with $0.05 \%$ $\mathrm{CH}_{4}$ and $8 \% \mathrm{O}_{2}$ in Ar over fresh ceria samples (panel A), with an additional of $20 \mathrm{ppm} \mathrm{SO}_{2}$ present (panel $\mathrm{B}$ ) and after $\mathrm{SO}_{2}$ exposure (panel C). The ramp rate for both cooling (dashed) and heating (solid) was $5^{\circ} \mathrm{C} / \mathrm{min}$. The consecutive cycle numbers are marked.

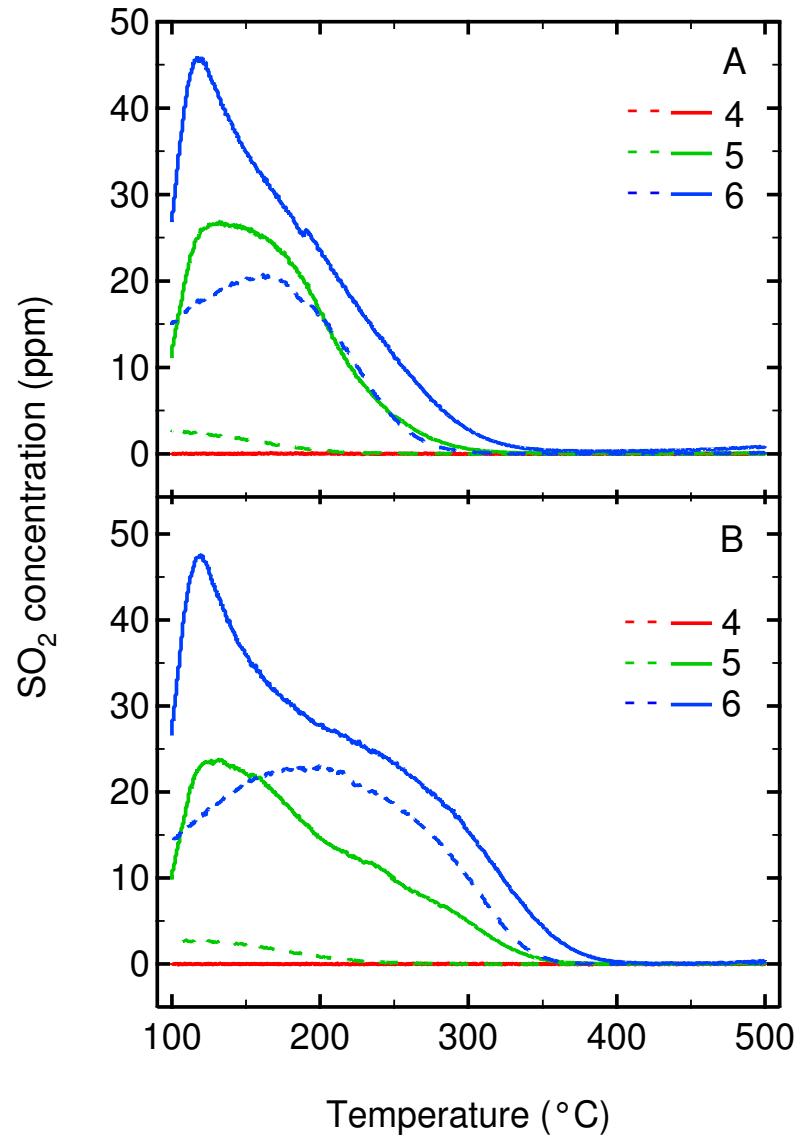

Fig. 3. Measured concentration of $\mathrm{SO}_{2}$ in the reactor outlet during cycle 4-6 for the temperature programmed reaction experiments with $\mathrm{Pt} /$ ceria samples (panel A) and ceria samples (panel B). The inlet $\mathrm{SO}_{2}$ concentration was $20 \mathrm{ppm}$. 

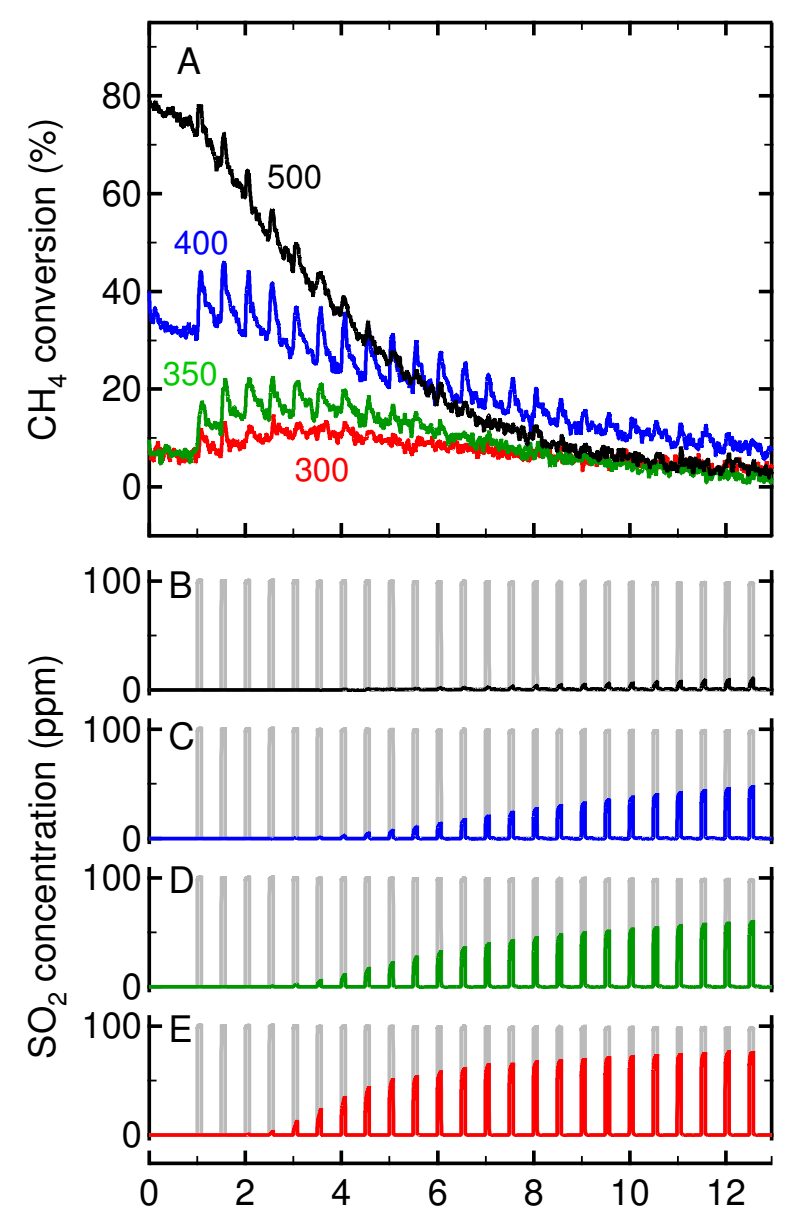

Time (h)

Fig. 4. Transient $\mathrm{SO}_{2}$ exposure experiments (100 ppm $\mathrm{SO}_{2}$ for 5 min) with $\mathrm{Pt} /$ ceria samples carried out at isothermal conditions at 300 , 350,400 and $500^{\circ} \mathrm{C}$. Panel A displays the methane conversion as a function of time on stream and panel $\mathrm{B}-\mathrm{E}$ show the response in $\mathrm{SO}_{2}$ concentration in the reactor outlet at the respective temperature $\left(500-300^{\circ} \mathrm{C}\right)$ together with the corresponding concentration profile for the empty reactor. Continuous inlet feed of $0.05 \% \mathrm{CH}_{4}$ and $8 \%$ $\mathrm{O}_{2}$ in $\mathrm{Ar}$.

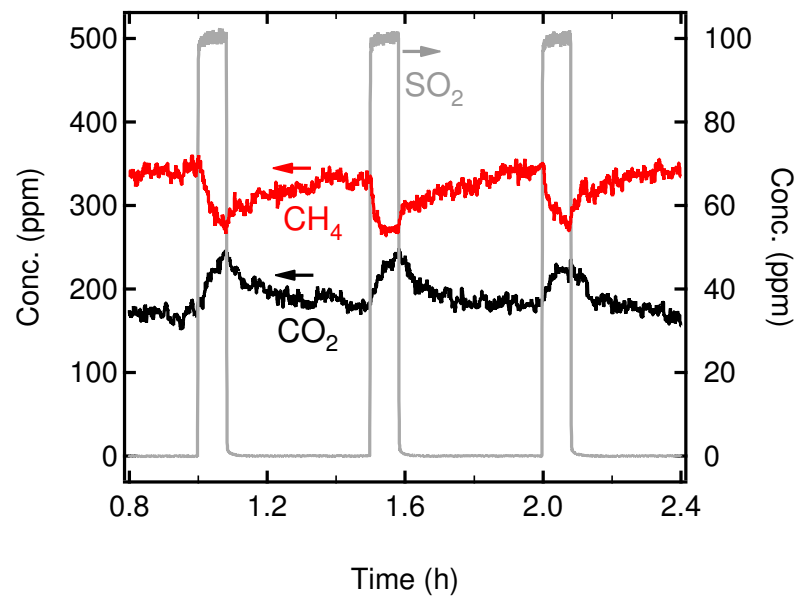

Fig. 5. Measured concentrations of $\mathrm{CH}_{4}$ and $\mathrm{CO}_{2}$ in the reactor outlet during the first three sulfur exposure periods (100 $\mathrm{ppm} \mathrm{SO}_{2}$ for $5 \mathrm{~min}$ ) for the transient $\mathrm{SO}_{2}$ exposure experiment carried out at $400^{\circ} \mathrm{C}$. The outlet $\mathrm{SO}_{2}$ concentration for the empty reactor is included as well. Continuous inlet feed of $0.05 \% \mathrm{CH}_{4}$ and $8 \% \mathrm{O}_{2}$ in Ar.

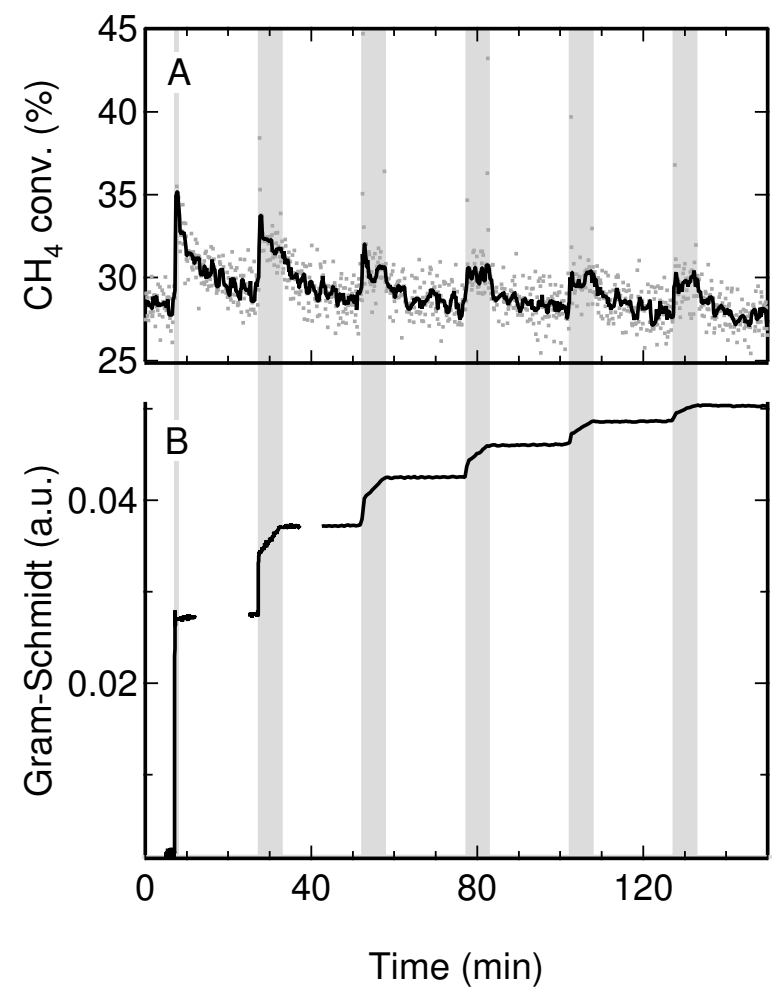

Fig. 7. Transient $\mathrm{SO}_{2}$ exposure experiments carried out in the DRIFTS cell at $450^{\circ} \mathrm{C}$ with $\mathrm{Pt} /$ ceria samples. Continuous feed of $0.05 \% \mathrm{CH}_{4}$ and $8 \% \mathrm{O}_{2}$ with intermittent exposure of $40 \mathrm{ppm} \mathrm{SO}_{2}$ (shaded area). Methane conversion (A) and total absorbance between 4000 and $900 \mathrm{~cm}^{-1}$ (B) are plotted versus time. 


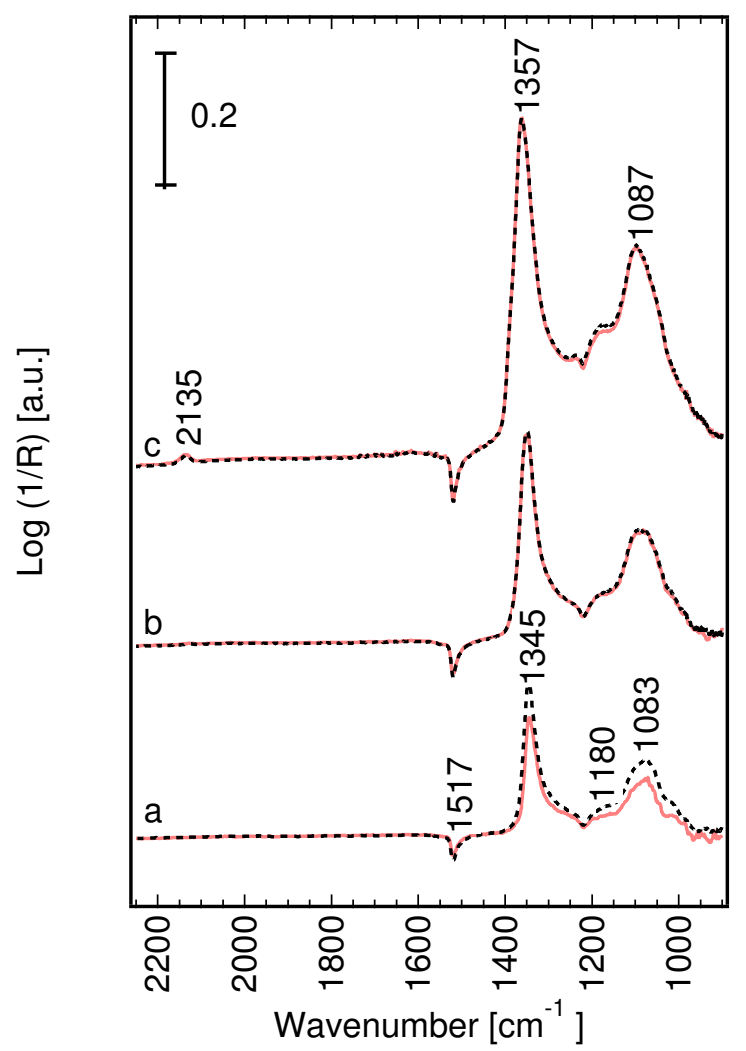

Fig. 8. Transient $\mathrm{SO}_{2}$ exposure experiments performed in the DRIFT cell at $450^{\circ} \mathrm{C}$ with $\mathrm{Pt} /$ ceria samples. Spectra collected at the end of the $\mathrm{SO}_{2}$ exposure periods $(-)$ are shown along with each spectra collected at the end of the subsequent sulfur-free periods (- -) for the first (a), second (b) and sixth (c) exposure period.

14 